\title{
Modeling of a negative ion source II. Plasma-gas coupling in the extraction region
}

\author{
F. Taccogna ${ }^{\mathrm{a}, \mathrm{b}^{*}}$, R. Schneider ${ }^{\mathrm{a}}, \mathrm{S}$. Longo ${ }^{\mathrm{b}, \mathrm{c}}$ and M. Capitelli ${ }^{\mathrm{b}, \mathrm{c}}$ \\ ${ }^{a}$ Max Planck Institute für Plasmaphysik, EURATOM Association, Wendelsteinstrasse 1, Greifswald, \\ D- 1749, Germany. \\ ${ }^{b}$ Istituto di Metodologie Inorganiche e di Plasmi IMIP-CNR, Sect. Bari, via Orabona 4, Bari,I-70126, \\ Italy \\ ${ }^{c}$ Dip. di Chimica, Universita'degli Studi di Bari, via Orabona 4, Bari,I-70126, Italy
}

PACS: 52.65.Cc; 52.65.Rr; 52.40.Hf

\begin{abstract}
The production, destruction and transport of $\mathrm{H}^{-}$in the extraction region of a negative ion source are investigated with a $1 \mathrm{D}(\mathrm{z})-3 \mathrm{~V}$ Particle-in-Cell electrostatic code. The motion of charged particles $\left(\mathrm{e}, \mathrm{H}^{+}, \mathrm{H}_{2}{ }^{+}\right.$and $\left.\mathrm{H}^{-}\right)$in their self-consistent electric field is coupled with the neutral particles $\left[\mathrm{H}(\mathrm{n}=1)\right.$ and $\left.\mathrm{H}_{2}\left(\mathrm{X}^{1} \Sigma_{\mathrm{g}}^{+}, v=0, \ldots, 14\right)\right]$ dynamics and vibrational kinetics of $\mathrm{H}_{2}$. Neutral influxes into the domain are determined by the simulation of the expansion region. Surface and volumetric processes involving plasma and neutrals have been included by using different Monte Carlo Collision methods. Calculations show the influence of the plasma grid bias and of the magnetic filter on the plasma parameter profiles. In particular, a transition from classical to complete reverse sheath is observed using a positively biased plasma grid. The influence of the magnetic filter is small. The importance of the hot-atom mechanism on the surface negative ion production is shown.
\end{abstract}

* corresponding author: taccogna@ipp.mpg.de 


\section{INTRODUCTION}

This work represents the extension of the Part I [1], where the neutral population was prepared in the expansion region of the radio frequency inductively coupled plasma (RF-ICP) hybrid negative ion source developed at IPP Garching [2]. This source is considered hybrid in the sense that surface produced negative ions on the plasma grid PG surface (by positive ions and neutrals conversion) are added to the volume produced negative ions in the bulk (by electron attachment to vibrational excited molecular states).

In order to obtain negative ion beams with higher efficiency, it is essential to understand the fundamental principles of such sources. Plasma parameters in the region next to the plasma grid $\mathrm{PG}(<3 \mathrm{~cm})$ are considered influential to the amount of effective extractable $\mathrm{H}^{-}$ current from an ion source. In this region, gradients due to the plasma sheath (modified by a biased PG and by the presence of a magnetic filter) create forces strongly affecting not only the free flight but also collisional events involving $\mathrm{H}^{-}$ions produced in the bulk and on the PG surface. In fact, experiments and models [3-7] have shown that PG bias and magnetic filter play an important role for the enhancement of $\mathrm{H}^{-}$production and extraction (through the electron temperature and density and through the plasma potential variations).

In this region, a non-homogeneous magnetic filter parallel to the PG is present, in order to keep the 'hot' electrons generated by the RF in the driver region away from the extraction region (tandem configuration). The cooling-down of electrons from the expansion region is further assisted by magnets in the extraction electrode which are primarily there to deflect and suppress the co-extracted electrons. In this source, the extraction current density of negative ions is strongly increased by adding evaporated Cs onto the Mo PG surface lowering its work function.

On the basis of these introductory features it is important to have a self-consistent model of the extraction region coupling the plasma with the neutral system.

Many zero-dimensional codes [8,9] have been developed in the last two decades. These models take into account the most important production/destruction $\mathrm{H}^{-}$volume processes and recently, processes involving Cs have also been included into the bulk [9]. However, in these models, neutrals and plasma profiles are averaged and self-consistent transport is completely missing. For this reason, different one or two dimensional fluid models [10,11] and pure Monte Carlo codes [12-15] have been developed and applied to the analysis of the magnetic filter effect. In particular, the latter ones have been used to the analysis of $\mathrm{H}^{-}$transport process 
in "real space" (calculation of the extraction probability) [12,13] and in "velocity space" (understanding of the $\mathrm{H}^{-}$velocity distribution and temperature) $[14,15]$.

Only recently, the first Particle-in-Cell models have been appeared [16-21]. Nevertheless, they suffer from some incompleteness. Previous PIC models used non-realistic plasma parameters and physical quantities (low plasma density and low magnetic field) or they do not take into account the coupling with the neutral system or the $\mathrm{H}^{-}$surface production selfconsistently.

For this reason, the approach we have followed is to solve the kinetic equations for charged particles by the Particle-in-Cell (PIC) method [22,23] and for neutral particles by Direct Simulation Monte Carlo (DSMC) technique [24]. Differently from the treatment done in the expansion region [1], where the plasma subsystem was considered as a fixed background, in the extraction region a strong coupling between plasma and neutral is present. Indeed, in this region the plasma dynamics strongly drives the physics and due to the magnetic filter effect, plasma density and temperature goes down.

The paper is organized as follows: in section II, we describe the numerical model, explaining the plasma and neutral modules including the implementation of bulk and boundary phenomena. In sect. III numerical results are presented and physical considerations relevant to the role of magnetic filter, PG bias and surface production, are discussed.

\section{NUMERICAL MODEL}

The region simulated (sketch represented in Fig. 1) is one-dimensional representing the behavior normal to the PG surface and starting $3 \mathrm{~cm}$ upstream from the extraction aperture of the PG. Uniformity in transverse $x$ and $y$ directions is considered. The choice of the size of the simulation domain is due to different reasons:

a) a quasi-neutral situation is present at the entrance and therefore no axial gradient effects are missing;

b) the effect of the magnetic filter is included in this region;

c) due to an electron temperature larger than $3 \mathrm{eV}$ in the bulk of the expansion region, the extraction probability of negative ions goes to zero if they are produced at a location greater than $3 \mathrm{~cm}$ from the PG, as demonstrated by previous models (see Fig. 3 in Ref. [12]). 
Charged and neutral particles dynamics are alternately solved in different modules and coupled explicitly. Every module use a different cell size and time step adequate to the plasma and gas dynamics respectively. This guarantees an accurate steady-state representation of the system. We are not interested in the temporal evolution of the system.

\section{A. Plasma Particle-in-Cell (PIC) Module}

Within the PIC module, only charged particles are moved and the code does not follow the dynamic of the neutrals but rather treats the latter as a fixed background with density, velocities and $\mathrm{H}_{2}$ vibrational distribution profiles calculated from the steady-state of previous iterations of the neutral module (see next paragraph II.B). The complete motion of electrons and different ion species $\left(\mathrm{H}^{+}, \mathrm{H}_{2}{ }^{+}\right.$and $\mathrm{H}^{-}$are simulated) is calculated in the self-consistent electric $E_{\mathrm{z}}$ and applied magnetic fields $B$ by solving the equations of motion for the coordinate $z$ and all the three component of velocity:

$$
\begin{gathered}
\frac{d z}{d t}=v_{z} \\
m \frac{d \mathbf{v}}{d t}=q(\mathbf{E}+\mathbf{v} \times \mathbf{B})
\end{gathered}
$$

using the Boris-Buneman version of the leap-frog methodology [23]. The time step is set equal to the inverse plasma frequency $\omega_{\mathrm{p}}$. A uniform spatial grid (cell size smaller than Debye length $\Delta z<\lambda_{\mathrm{D}}$ ) is used for the electric potential calculation:

$$
\frac{\partial^{2} \phi}{\partial z^{2}}=-\frac{\rho}{\varepsilon_{0}}
$$

as typical in a PIC cycle. The direction of the magnetic filter field $B$ is parallel to the PG. Its spatial profile is given by the Gaussian behaviour:

$$
B_{y}(z)=B_{\text {peak }} \exp \left\lfloor-\left(\frac{z-z_{\text {peak }}}{l_{z}}\right)^{2}\right\rfloor
$$


with $z_{\text {peak }}=0.017 \mathrm{~m}, l_{\mathrm{z}}=3 \times 10^{-4} \mathrm{~m}$ (the axial position $z$ is also in meter) and $B_{\text {peak }}=4 \mathrm{mT}$ (see Fig. 2). Even if the model is one-dimensional in the direction normal to the PG surface, the magnetic field (parallel to the surface) effect is included. In fact, it is simulated a region surrounding an extraction hole supposing a periodicity in the transverse dimensions $x$ (normal to the field lines) and $y$ (along the field lines). When a particle leaves the region in a direction $x$ or $y$, another particle is supposed to come from the opposite direction. This means that each virtual particle represents a charge per unit surface. Of course, a more self-consistent 2D model is necessary.

The initial condition for the calculation is an empty computational region. An ambipolar particle source is located at the left boundary of the system and it is of finite size, so that quasi-neutrality near the source region is maintained by the plasma itself. We call this boundary the plasma line (PL) and a Neumann boundary condition for the Poisson equation (2) is used: $\partial \phi /\left.\partial z\right|_{\mathrm{PL}}=0$. The velocities of injected particles $\left(\mathrm{e}, \mathrm{H}^{+}\right.$and $\left.\mathrm{H}_{2}{ }^{+}\right)$are chosen from an half Maxwellian distribution function with bulk density $\mathrm{n}_{0, \mathrm{p}}$, source strength $\mathrm{S}_{0 \mathrm{j}}$ and source temperature $\mathrm{T}_{0 \mathrm{j}}$ taken from experimental measurements [25] (see Table I). No negative ions are injected from the expansion region. Due to the high electron temperature all the possible negative ions created are supposed to be destroyed by electron detachment. In order to reproduce the plasma flow detected by measurements using a Mach probe [25], an axial drift component is added to the thermal one: $v_{\mathrm{z}, \mathrm{drift}}=0.3 \mathrm{Mach}$. If particles cross the PL from right to left, a refluxing method is used (particles are re-injected with bulk parameters).

As shown in Fig. 1, two different axial lines are simulated: line A ending on one hole (open boundary condition: $\partial \phi /\left.\partial z\right|_{\mathrm{PG}}=0$ ) and line B ending on the PG surface (fixed potential $\phi_{\mathrm{PG}}$ ).

Volumetric collisional effects are included via different Monte Carlo techniques [26] (see Table II for the complete list of collisions). Among the different processes, particular emphasis is pointed to those involving production and destruction of negative ions.

It is generally accepted that negative ions are produced in the volume through the electron dissociative attachment eDA (reaction (9) in Table II) of low-energy electrons $(1 \mathrm{eV})$ to the vibrationally excited molecules in ground electronic state. Only the contribution of the ${ }^{2} \sum_{\mathrm{u}}^{+}$ resonant state of $\mathrm{H}_{2}^{-}$is considered in the cross section [27]. In fact, the eDA cross sections increase by five orders of magnitude when the hydrogen molecules are vibrationally excited from $v=0$ to $v=5$, and stay constant at higher $v$. Moreover, the eDA cross sections peak at threshold and the threshold energy goes down when $v$ goes up. This reaction is exoergic for $v>9$, which corresponds to an internal energy beyond $3.994 \mathrm{eV}$, the difference between the 
potential energy of the nuclei at equilibrium internuclear separation $\left(E_{\text {diss }}=4.748 \mathrm{eV}\right)$ and the electron affinity of $\mathrm{H}\left(E_{\mathrm{A}}=0.754 \mathrm{eV}\right)$. For a given incident electron energy $E_{\mathrm{e}}$, the conservation of total energy provides the energy of the negative ion formed, namely:

$$
E_{H-}=\frac{1}{2}\left(E_{e}-3.994+E_{H 2}(v)\right)
$$

where $E_{\mathrm{H} 2}(v)$ is the internal energy of the vibrational level $v$. More energetic ions are formed when the attachment process is exoergic, and even the most energetic $\mathrm{H}^{-}$ions cannot have energies greater than $0.5 \mathrm{eV}$, as showed in Ref. [30]. When created, $\mathrm{H}^{-}$ions are launched isotropically. Negative ion production via the Rydberg states [31] is neglected. It is difficult to examine the incertitude of this assumption because the conclusions on the importance of Rydberg states in affecting the negative ion kinetics by Hiskes [32] and by Hassouni et al. [33] are strongly different (see paragraph VI in Ref. [34]).

Concerning the destruction processes, three volume reactions are considered important: electron detachment in collisions with electrons [29] (reaction (15) in Table II), mutual neutralization in collision with positive ions [29] (reaction (16) in Table II) and associative detachment in collisions with atoms [29] (reaction (18) in Table II). Due to the decreased plasma density by the magnetic filter and the high value of the cross section without a presence of a threshold, the last one is particularly important.

Finally, particularly important are also non-destructive collision reactions as elastic collisions with $\mathrm{H}^{+}$[29] and charge exchange collisions with $\mathrm{H}$ [29] by changing the transport and reducing the kinetic energy of the extracted $\mathrm{H}^{-}$.

When a charged particle hits the PG wall (only in line B case) different processes are possible. Among them, the most important concerning caesiated surface is the formation of negative ions by positive ions [35]. As proofed in [36] [see Figs. 7 and 10 there], the yields $Y\left(E_{\text {in }}\right)$ of $\mathrm{H}^{-}$ions produced in backscattering of $\mathrm{H}^{+}$and $\mathrm{H}_{2}{ }^{+}$ions in the energy range $E_{\text {in }}=2-20$ $\mathrm{eV}$, is the same for both ions, indicating that all molecular ions are dissociated before colliding with the converter surface.

The numerical implementation of this process is accomplished expressing the $\mathrm{H}^{-}$yield as a function of positive ion incident energy $E_{\text {in }}$ by the following formula [36]: 


$$
Y\left(E_{\text {in }}\right)=R_{N} \eta_{0}\left(1-\frac{E_{\text {th }} / R_{E}}{E_{\text {in }}}\right), \quad E_{\text {in }} \geq E_{\text {th }} / R_{E}
$$

which reflects the two-steps idealization of the mechanism: the backscattering as neutral atom and the electron transfer. The yield is completely characterized by the two parameters, $R_{\mathrm{N}} \eta_{0}$ and $E_{\mathrm{th}} / R_{\mathrm{E}}$, where $R_{\mathrm{N}}$ and $R_{\mathrm{E}}$ are the particle and energy reflection coefficients, respectively, while $\eta_{0}$ is the height and $E_{\mathrm{th}}$ is the threshold energy for the electron transfer probability, approximated as an Heaviside function (see Figs. 3,4 in Ref. [37]). Fitting formula depending on the incident energy $E_{\text {in }}$ are used for reflection coefficients (see Ref. [38]). The $\mathrm{H}^{-}$surface ions are launched from the surface with energy $R_{\mathrm{E}} E_{\text {in }}$ and with a cosine distribution angle emission. This value is very important in overcoming the natural potential barrier forming in front of PG surface. All the parameters used for a Caesiated Mo surface are summarized in Table III.

\section{B. Neutral Direct Simulation Monte Carlo (DSMC) Module}

Every 1000 PIC cycles, when a quasi-steady state plasma condition is reached (in order to allow the ion system to relax), the neutral module is called. The method reported in the Part I [1] is used, that is neutral particles are tracked in a plasma background from the previous steady state PIC module call. Only the ground electronic state of atomic hydrogen $\mathrm{H}(\mathrm{n}=1 \mathrm{~s})$ is considered $\mathrm{H}(\mathrm{n}=1 \mathrm{~s})$, while for the molecules, the fifteen vibrational levels of the fundamental electronic state of $\mathrm{H}_{2}\left(\mathrm{X}^{1} \sum_{\mathrm{g}}^{+}, v=0, \ldots, 14\right)$ are taken into account. Neutral pseudo-particles are launched at the entrance with a half maxwellian velocity distribution (neutral density, $\mathrm{H} / \mathrm{H}_{2}$ density ratio, translational temperature and molecular vibrational distributions are taken from Part I [1] and listed in Table I). Different weights (two order of magnitude larger than used for charged particles in the PIC module), cell sizes (of the order of neutral mean free path) and time steps are used in the neutral module. All the collisions considered are those reported in Table II of Part I [1]. The volumetric effect of the Cs is neglected due to the low value of the density (two orders of magnitude less than plasma density as measured in Ref. [39]). In fact, in this source, Cs is supposed to influence only surface processes by reducing the surface work function.

Neutrals are also launched from the surface as a consequence of positive ions neutralization (half-maxwellian according to the averaged positive ion particle fluxes calculated during the PIC module) with molecular vibrational distributions depending on the 
averaged ion energy fluxes to the wall. Moreover, a wide spectrum of vibrationally excited molecules can be formed in the recombinative desorption process of atomic hydrogen on some metal surfaces by Eley-Rideal and hot-atom reactions [40].

The most important mechanism added to the neutral module used in the expansion region is the direct negative ion production from the caesiated PG surface by neutral impact. This mechanism is very important due to the fact that the magnetic filter, preventing the extraction of electrons from the plasma, decreases also the $\mathrm{H}^{+} / \mathrm{H}_{2}{ }^{+}$flux on the plasma grid but does not change the $\mathrm{H} / \mathrm{H}_{2}$ flux. Consequently, the negative ion surface production originates mainly from atoms and molecules. Two types of negative ion emission are considered: thermodynamic and non-thermodynamic equilibrium surface ionization [41]. In the first case, atoms impinging on a metal surface may be emitted as atoms or ions in a subsequent evaporation processes after mean residence times long enough for the establishment of equilibrium. In this case, the probability of leaving the surface as a negative ion depends on the difference between the electron affinity $E_{\mathrm{A}}$ and the work function of the surface $\Phi$ and is given by the Langmuir-Saha relation [42]:

$$
Y=\frac{1}{1+\frac{g_{0}}{g_{-}} e^{\left(\phi-E_{A}\right) / k T_{H}}}
$$

where $g_{0}$ ang $g$ - are the degeneracy of atom and negative ion respectively and $T_{\mathrm{H}}$ is the atom temperature.

The second mechanism, called also hot-atom process as in the positive ions conversion case, is the result of the interaction of a fast neutral with the surface and the equation for the negative surface ionization of hydrogen ions $\mathrm{H}^{+} / \mathrm{H}_{2}^{+}$[eq. (5)] is used with different values of parameters $R_{\mathrm{N}} \eta_{0}$ and $E_{\mathrm{th}} / R_{\mathrm{E}}$ (see Table III). In fact, as pointed out in the last paragraph, the ions are neutralized approaching the surface and the mechanism becomes identical for ions and neutrals.

When the neutral subsystem reaches a steady state, the plasma module is called again with the latest neutral results. This iteration is repeated until convergence of the overall system.

\section{RESULTS AND DISCUSSIONS}


In all the different cases studied, $10^{11}$ real charged particles are represented by one superparticle. The maximum number of superparticles used varies between $10^{5}$ and $10^{6}$. Fig. 3(a) shows the time evolution of the different number of charged macroparticles (electrons, positive ions $\mathrm{H}^{+}$and $\mathrm{H}_{2}{ }^{+}$, negative ions $\mathrm{H}^{-}$) in the entire simulation domain for the case $B_{\text {peak }}=4 \mathrm{mT}$ and $\Phi_{\mathrm{PG}}=0 \mathrm{~V}$. For the quasi-steady state to be reached, it takes about some ion transit times $(\sim 10 \mu \mathrm{s})$ (longer for the case of a strong magnetic filter). As it can be seen the last to reach a steady state value are negative ions. Fig. 3(b) shows the time evolution up to $0.5 \mathrm{~ms}$ of the number of neutral macroparticles (each macroparticle represents $10^{13}$ real atoms $\mathrm{H}$ or molecules $\mathrm{H}_{2}$ ). It is evident that even if the number of atoms injected is larger than molecules (results coming from the expansion region simulation [1]), at the steady state, the ratio of atoms to molecules reaches a value of about 0.3 , in very good agreement with the experimental value measured $4 \mathrm{~cm}$ from the PG [39], which is 0.2 . This decrease is due to the fact that the dissociation rate drops down in the extraction region (due to the electron temperature decreasing), while the wall recombination rate remains high.

\section{A. Axial profiles towards PG surface and extraction hole}

Fig. 4 shows the plasma potential $3 \mathrm{~cm}$ from PG for the two different lines considered, extraction hole (broken line A) and PG surface biased at $\phi_{\mathrm{PG}}=0 \mathrm{~V}$ (full line B) using a magnetic filter strength $B_{\text {peak }}=4 \mathrm{mT}$. Typically, the plasma potential reaches a flat value, the bulk value $(\sim 15 \mathrm{~V})$ within $1 \mathrm{~cm}$ from PG in agreement with experimental results [25]. In the case of the extraction hole, the potential remains almost constant. In fact, due to the absence of plasma-wall interaction, the quasi-neutrality is kept all along the entire axial domain.

Figs. 5 show the axial profiles of the corresponding charged particles density for the two different cases. The known phenomenology of plasma-wall transition region is retrieved: the plasma is neutral at the bulk, while a classical space charged region (the electron-repelling sheath) develops in contact to the grid. The most important visible effect comparing the two cases is the contribution of surface processes to the negative ion production (green lines). The negative ion density near the wall increases by one order of magnitude in the case of the PG line, in agreement with recent experimental measurements [43]. For this reason the plasma density near the grid increases also, reducing the insulating properties of the sheath and the sheath size as well. However, it has to be pointed out that a complete model including radial 
transport between lines $\mathrm{A}$ and $\mathrm{B}$ requires a complete 2D model that will represent the next step.

In this source it is crucial to understand the role of atomic H. A high power source is very efficient to dissociate molecules and create hot atoms. They are the most important source of $\mathrm{H}^{-}$by means of the hot-atom mechanism on the surface ionization, as already pointed out in paragraph II.B. Fig. 6 shows the $\mathrm{H}^{-}$density axial profiles coming from the different contributions (bulk production, surface production by ions and surface production by neutrals). As it is evident, $0.5 \mathrm{~cm}$ from the wall, the negative ions are produced mostly by the hot-atom mechanism reaching a maximum value of $4 \times 10^{17} \mathrm{~m}^{-3}$ on the $\mathrm{PG}$ surface. The contribution from bulk electron attachment is relatively small there (due to the electron density drop) and it has some relevance into the bulk reaching a maximum value of $3 \times 10^{16} \mathrm{~m}^{-}$ ${ }^{3}$. Almost insignificant is the role of ionic surface conversion due to the drop of positive ion density close to the PG. However, neutrals represent also the most important destruction mechanism of $\mathrm{H}^{-}$through the associative detachment, as is evident from Fig. 7, where we have calculated the reaction rate of the different processes involving the production and destruction of negative ions.

\section{B. Magnetic filter effect}

In this section, we discuss the role of the magnetic filter, comparing three different simulations performed for maximum filter strengths $B_{\text {peak }}$ of $0 \mathrm{mT}, 4 \mathrm{mT}$ and $8 \mathrm{mT}$, using the same analytical expression [eq. (3)] in all the cases.

It is well known experimentally [6,7] that the magnetic filter reduces the temperature and density of electrons in the extraction region compared to the value reached in the expansion chamber. In fact, the electron diffusion coefficient across the magnetic field is given by:

$$
D_{\perp}=\frac{D_{\|}}{\left[1+\left(\omega_{c e} / v\right)^{2}\right]}
$$

where $D_{\|}=k_{\mathrm{B}} T_{\mathrm{e}} / m v, \omega_{c e}$ and $v$ are the diffusion coefficient in the absence of magnetic field, cyclotron frequency, and total collision frequency, respectively. In cold dense plasmas $\left(n_{\mathrm{e}}>10^{17} \mathrm{~m}^{-3}\right)$ and low gas pressures $(p<5$ mtorr), which are typical for the expansion region, Coulomb collisions dominate the total electron elastic collisions $\left(v \propto T_{\mathrm{e}}^{-3 / 2}\right)$. Moreover, if the 
magnetic field is strong enough and the conditions $\omega_{\mathrm{ce}}>>v$ and $r_{\mathrm{ce}}<<L_{\mathrm{z}}\left(r_{\mathrm{ce}}\right.$ is the electron Larmor radius and $L_{z}$ is the transverse dimension of the filter field region) are satisfied, then electrons are magnetized. Once the electrons are magnetized, the electron diffusion coefficient across the magnetic field becomes $D_{\perp} \approx r_{c e}{ }^{2} v \propto T_{e}^{-1 / 2}$. As a result, hot electrons have a low diffusion coefficient compared with the cold electrons and therefore the electron density and temperature $T_{\mathrm{e}}$ decreases through the filter region. This is confirmed in Fig. 8, where the axial behaviour of electron temperature with and without the magnetic filter is plotted. Most of the temperature drop takes place in region located beyond the magnetic field peak position $(z=-0.013 \mathrm{~m})$, while in the absence of magnetic filter, the electron temperature remains almost constant all along the entire extraction region dropping just very close to the PG surface.

In Fig. 9 we have compared the electron and negative ion $\mathrm{H}^{-}$density profiles with and without magnetic filter. The electron density decreases with magnetic filter, due to the fact that the fraction of electrons able to transverse the filter falls off with increasing field strength as discussed before. On the other hand, the negative ion density profile remains almost unchanged. In fact, although the reaction rate for the dissociative attachment which produces bulk $\mathrm{H}^{-}$increases with the decrease of the electron temperature, the production rate decreases also with the decrease of electron density. Concerning the surface production by positive ions, it is beneficial to have a larger plasma density near the plasma grid. Therefore, the unchanged $\mathrm{H}^{-}$density profile in Fig. 9 confirms once again that the $\mathrm{H}^{-}$production is dominated by surface neutral conversion (and in particular the hot-atom process), which is not influenced by the magnetic filter. In general, the magnetic filter does not enhance the negative ion density itself, but increases the negative ion to electron density ratio in the extraction region, helping in this way the suppression of the electron current extracted.

\section{Plasma grid bias effect}

The extracted negative ion current and electron current appeared to be sensitive to the bias potential applied to the PG surface [2,25,44-46]. It is observed that there is an optimal bias voltage for a particular source and this optimal bias potential is close to the plasma potential of that source. When the bias voltage (positive polarity) of the PG is increased up to the plasma potential, negative ion current increases, while the electron current and the electron density decreases. But above that optimal bias voltage, both the currents and density decrease with different rate [46]. In fact, with proper biasing a complete suppression of the coextracted electron current is possible [44] without much reduction in the negative ion currents. 
To explain these observations, different interpretations have been done:

a) an $\mathbf{E} \times \mathbf{B}$ drift effect on negative charged particles, where the electric field $\mathbf{E}$ is due to positive grid bias, while the magnetic field $\mathbf{B}$ is the parallel to the surface filter;

b) M. Bacal et al. [4] suggested that due to the positive bias the plasma grid depletes the electron population near by and to compensate that depletion of electrons and to maintain the charge neutrality, negative ions from the volume plasma try to come there and increase the negative ion density;

c) with no bias, the plasma potential in the bulk is positive relative to PG and the negative ions as well as the electrons are electrostatically trapped, i.e. the plasma is a potential well for them. In order to "climb out" this barrier ( $\sim k_{\mathrm{B}} T_{\mathrm{e}}$ if there were only electrons and positive ions) they should have enough energy, unless PG is biased at a potential close to the plasma potential. In fact, photodetachment measurements [47] effected near the PG of the source Camambert III showed that the $\mathrm{H}^{-}$gain a directed velocity towards the grid varying from 0.5 $c_{\mathrm{s}}$ (very close to thermal velocity) at $\Phi_{\mathrm{PG}}=0 \mathrm{~V}$ up to $0.95 c_{\mathrm{s}}$ at $\Phi_{\mathrm{PG}}=4 \mathrm{~V}$ (the plasma potential in that experiment is lying between 2 to $3 \mathrm{~V}$ ).

It is important to point out that all the previous interpretations refer to the volume production negative ions. In a hybrid source, the reverse sheath helps not only the bulk-produced negative ions extraction, but it push also back in the direction of the extraction hole, the negative ions produced on the surface and moving otherwise into the bulk, that is in the direction opposite to the extraction grid.

In fact, as shown in Fig. 10, where the electric potential profiles using different bias voltage $\Phi_{\mathrm{PG}}(0 \mathrm{~V},+10 \mathrm{~V},+20 \mathrm{~V}$ and $+36 \mathrm{~V})$ are shown, a transition from a classical sheath drop to a complete reversed sheath is visible using a positive bias. The potential profile acquires the characteristic curve already observed experimentally [25] and in agreement with the hypothesis of the formation of a double layer in the region close to the $\mathrm{PG}$, where the $\mathrm{H}^{-}$ions are formed due to surface production process. The positive bias potential on the plasma grid can be considered as an extraction field for $\mathrm{H}^{-}$ions. Furthermore, the plasma potential in the bulk is slightly affected by the PG bias due to the effect of the limited size of the simulation domain (3 $\mathrm{cm}$ from PG). In fact, in the presence of a magnetic filter, the plasma potential in the bulk remains almost unchanged by the PG bias as shown experimentally in Ref. [25].

Fig. 11 shows the e/ $\mathrm{H}^{-}$density axial profiles in two cases: $0 \mathrm{~V}$ and $+36 \mathrm{~V}$ PG biased. For positively biased grid, electron density is reduced drastically and the depletion is extended 1.5 cm inside the plasma from the PG. Differently to what claimed by hypothesis b), even the $\mathrm{H}^{-}$ 
ion density is reduced. However, the ratio $\mathrm{H}^{-} / \mathrm{e}$ increases in the case of positively biased $\mathrm{PG}$. This results excludes the second hypothesis b) as the reasons why the negative ion current increases with positively biased PG. In this case, the negative ion current enhancement is simply due to the transition of the negative ion type flow, from thermal flow in the case of no bias to directed flow in the case of positively PG bias. This is confirmed comparing the $\mathrm{H}^{-}$ axial temperature profile with and without bias reported in Fig. 12. It is calculated as the mean square-spread in the velocity component $v_{\mathrm{z}}[48]$ :

$$
T_{z}=\frac{M}{3 k_{B}}\left(\left\langle v_{z}^{2}\right\rangle-\left\langle v_{z}\right\rangle^{2}\right)
$$

where the angular brackets denote averages over the set of test particles: $\langle x\rangle=\frac{1}{N} \sum_{i=1}^{N} x_{i}$. The effect of the bias is to reduce the $\mathrm{H}^{-}$temperature, creating an $\mathrm{H}^{-}$beam toward the $\mathrm{PG}$ surface. Furthermore, the reduction of the temperature of the negative ions is an important parameter of the negative ion source, since it affects the beam optics and determines the lower limit of the negative ion beam emittance.

\section{CONCLUSIONS AND OUTLOOK}

We have studied the negative ion formation and transport in the acceleration region a radio-frequency inductively coupled discharge. We used a fully self-consistent $1 \mathrm{D}(\mathrm{z})-3 \mathrm{~V}$ simulation code, coupling plasma dynamics via PIC technique and gas phase dynamics and vibrational kinetics under DSMC technique. The bulk kinetic, plasma-surface and gas-surface processes are included.

We have analyzed the influence of the PG bias voltage and magnetic filter simulating two different cases: the PG bias and the open boundary extraction hole. A complete reversed sheath is recovered for a positively biased which helps the extraction of negative ions, while an irrelevant role is found for the magnetic filter. The primary role of neutrals in the surface production through the hot-atom mechanism is underlined.

Future studies should include a second spatial transverse dimension. In fact, in order to have a realistic model of the extracted electron and $\mathrm{H}^{-}$ion current, a complete transport 
picture is needed in order to consider self-consistently the electron losses along the field lines of the filter magnetic field. Furthermore, this will allow understanding the role of the $\mathbf{E} \times \mathbf{B}$ drift which causes a transverse non-uniformity through out the extraction area impacting on the beam optics and divergence. The acceleration region will be simulated using as input data the results of the extraction region model.

Additional negative ion production channels (Rydberg states) have to be included as well. Finally, in order to include the temporal behavior due to the radio frequency character of the source the simulation will be coupled with a separate model of the driver region.

\section{Acknowledgments}

This work is supported by the European Community under the MARIE CURIE INTRAEUROPEAN FELLOWSHIP: "NNBI - Negative ion based Neutral Beam Injection system" and by MIUR-PRIN 2008: "Dinamica dei processi elementari per la chimica e la fisica dei plasmi". R. Schneider acknowledges funding of the work by the Initiative and Networking Fund of the Helmholtz Association. 


\section{REFERENCES}

1 F. Taccogna, R. Schneider, S. Longo, M. Capitelli, Phys. Plasmas 14, 073503 (2007).

2 U. Fantz, P. Franzen, W. Kraus, H. D. Falter, M. Berger, S. Christ-Koch, M. Fröschle, R. Gutser, B. Heinemann, C. Martens, P. McNeely, R. Riedl, E. Speth, D. Wünderlich, Rev. Sci. Instrum. 79, 02 A511 (2008).

3 K. N. Leung, K. W. Ehlers, M. Bacal, Rev. Sci. Instrum. 54(1), 56-61 (1983).

4 M. Bacal, F. Hillion, M. Nachman, Rev. Sci. Instrum. 56, 649-654 (1985).

5 M. Bacal, J. Brunetau, P. Devynck, Rev. Sci. Instrum. 59, 2152-2157 (1988).

6 T. Sakurabayashi, A. Hatayama, M. Bacal, J. Appl. Phys. 95(8), 3937-3942 (2004).

7 Y. Matsumoto, M. Nishiura, K. Matsuoka, M. Sasao, M. Wada, H. Yamaoka, Thin Solid Films 506-507, 522-526 (2006).

8 W. G. Graham, Plasma Sources Sci. Technol. 4, 281-292 (1995).

9 D. Pagano, C. Gorse, M. Capitelli, IEEE Trans. Plasma Sci. 35(5), 1247-1259 (2007).

10 A. J. T. Holmes, Plasma Sources Sci. Technol. 5, 453-473 (1996).

11 Ts. Paunska, H. Schlüter, A. Shivarova, Kh. Tarnev, Phys. Plasmas 13, 023504 (2006).

12 D. Riz, J. Pamela, Rev. Sci. Instrum. 69(2), 914-919 (1998).

${ }^{13}$ M. Bandyopadhyay, R. Wilhelm, Rev. Sci. Instrum. 75(5), 1720-1722 (2004).

${ }^{14}$ K. Makino, T. Sakurabayashi, A. Hatayama, K. Miyamoto, M. Ogasawara, Rev. Sci. Instrum. 73(2), 1051-1053 (2002).

15 P. Diomede, S. Longo, M. Capitelli, to appear on IEEE Trans. Plasma Sci., (2008).

${ }^{16}$ H. Naitou, O. Fukumasa, K. Sakachou, Rev. Sci. Instrum. 67(3), 1149-1151 (1996).

17 A. Hatayama, T. Matsumiya, T. Sakurabayashi, M. Bacal, Rev. Sci. Instrum. 77, 03A530 (2006).

18 P. Diomede, S. Longo, M. Capitelli, Rev. Sci. Instrum. 77, 03 A503 (2006).

${ }^{19}$ M. Turek, J. Sielanko, P. Franzen, E. Speth, in Proc. International conference Plasma 2005; AIP Conf Proc. no. 812, 153-156 (2006).

${ }^{20}$ D. Wunderlich, R. Gutser, U. Fantz, NNBI team, in Proc. 11th International Symposium on Production and Neutralization of Negative Ions and Beams, edited by M. P. Stockli, AIP Conf. Proc. no. 925, New York: American Institute of Physics, 46-57 (2007).

${ }^{21}$ M. Capitelli, M. Cacciatore, R. Celiberto, O. De Pascale, P. Diomede, F. Esposito, A. Gicquel, C. Gorse, K. Hassouni, A. Laricchiuta, S. Longo, D. Pagano, M. Rutigliano, Nucl. Fus. 46(6), S260-S274, (2006). 
22 J. W. Eastwood, R. W. Hockney, Computer Simulation using Particle, (New York: McGraw-Hill, 1981).

${ }^{23}$ C. K. Birdsall, A. B. Langdon, Plasma Physics via Computer Simulation, (New York: McGraw-Hill, 1985).

${ }^{24}$ G. A. Bird, Molecular Gas Dynamics and the Direct Simulation of Gas Flows (Oxford: Oxford Science, 1994).

${ }^{25}$ M. Bandyopadhyay, A. Tanga, H. D. Falter, P. Franzen, B. Heinmann, D. Holtum, W. Kraus, K. Lackner, P. McNeely, R. Riedl, E. Speth, R. Wilhelm, J. Appl. Phys. 96(8), 4107-4113 (2004).

${ }^{26}$ K. Nanbu, IEEE Trans. Plasma Sci. 28(3), 971-990 (2000).

${ }^{27}$ R. Celiberto, R. K. Janev, A. Laricchiuta, M. Capitelli, J. M. Wadehra, D. E. Atems, Atomic Data and Nuclear Data Tables 77, 161-213 (2001).

$28 \mathrm{http}: / / \mathrm{www}-\mathrm{cfadc}$.phy.ornl.gov.

${ }^{29}$ R. K. Janev, W. D. Longer, K. Evants, Jr., D. E. Post, Elementary Processes in HydrogenHelium Plasmas (Berlin: Springer, 1987).

30 J. M. Wadehra, Phys. Rev. A 29(1), 106-110 (1984).

31 L. A. Pinnaduwage, W. X. Ding, D. L. McCorkle, S. H. Lin, A. M. Mebel, A. Garscadden, J. Appl. Phys. 85(10), $7064-7069$ (1999).

32 J. Hiskes, Appl. Phys. Lett. 69, 755-757 (1996).

33 K. Hassouni, A.Gicquel, M. Capitelli, Chem. Phys. Lett. 290(4-6), 502-508 (1998).

${ }^{34}$ M. Capitelli, C. Gorse, IEEE Trans. Plasma Sci. 33(6), 1832-1844 (2005).

35 J. R. Hiskes, A. Karo, M. Gardner, J. Appl. Phys. 47(9), 3888-3896 (1976).

${ }^{36}$ M. Seidl, H. L. Cui, J. D. Isenberg, H. J. Know, B. S. Lee, S. T. Melnychuk, J. Appl. Phys. 79(6), 2896-2901 (1996).

37 H. L. Cui, J. Vac. Sci. \& Tec. A9(3), 1823-1827 (1991).

38 W. Eckstein, J. P. Biersack, Appl. Phys. A38, 123-129 (1985).

${ }^{39}$ U. Fantz, H. D. Falter, P. Franzen, E. Speth, R. Hemsworth, D. Boilson, A. Krylov, Rev. Sci. Instrum. 77, 03A516 (2006).

${ }^{40}$ M. Rutigliano, M. Cacciatore, G. D. Billing, Chem. Phys. Lett. 340, 13-20 (2001).

${ }^{41}$ Yu. Belchenko, Rev. Sci. Instrum. 64(6), 1385-1393 (1993).

42 J. Pelletier, C. Pomot, J. Cocagne, J. Appl. Phys. 50(7), 4517-4523 (1979).

${ }^{43}$ U. Fantz, H. Falter, P. Franzen, D. Wünderlich, M. Berger, A. Lorenz, W. Kraus, P. McNeely, R. Riedl, E. Speth, Nucl. Fus. 46(6), S297-S306 (2006). 
${ }^{44}$ O. Vollmer, B. Heineman, W. Kraus, P. McNeely, R. Riedl, E. Speth, R. Trainham, R. Wilhelm, Fusion Engineering and Design 56-57, 465-470 (2001).

${ }^{45}$ U. Fantz, P. Franzen, W. Kraus, M. Berger, S. Christ-Koch, M. Fröschle, R. Gutser, B. Heinemann, C. Martens, P. McNeely, R. Riedl, E. Speth, D. Wünderlich, Plasma Phys. Control. Fus. 49(12B), B563-580 (2007).

${ }^{46}$ P. Franzen, H. D. Falter, U. Fantz, W. Kraus, M. Berger, S. Christ-Koch, M. Fröschle, R. Gutser, B. Heinemann, S. Hilbert, S. Leyer, C. Martens, P. McNeely, R. Riedl, E. Speth, D. Wünderlich, Nucl. Fus. 47(4), 264-270 (2007).

47 A.A. Ivanov, A. B. Sionov, F. El Balghiti-Sube, M. Bacal, Phys. Rev. E55(1), 956-961 (1997).

48 K. Nanbu, S. Yonemura, J. Comp. Phys. 145, 639-654 (1998). 
Table I. Input data used for the simulation of the extraction region.

\begin{tabular}{lc}
\hline \hline Injected plasma density $\mathrm{n}_{0, \mathrm{p}}\left(\mathrm{m}^{-3}\right)$ & $3 \times 10^{17}$ \\
Plasma source strenght particle ratio: $\mathrm{S}_{0, \mathrm{e}} / \mathrm{S}_{0, \mathrm{H}+} / \mathrm{S}_{0, \mathrm{H} 2+}$ & $1 / 0.6 / 0.4$ \\
Plasma source temperatures $(\mathrm{eV}) \mathrm{T}_{0, \mathrm{e}} / \mathrm{T}_{0, \mathrm{H}+} / \mathrm{T}_{0, \mathrm{H} 2+}$ & $3 / 0.7 / 0.7$ \\
Axial drift velocity (Mach) $\mathrm{v}_{\mathrm{z}, \mathrm{drift}}$ & 0.3 \\
Injected gas density $\mathrm{n}_{0, \mathrm{n}}\left(\mathrm{m}^{-3}\right)$ & $4 \times 10^{19}$ \\
Gas source strenght particle ratio: $\mathrm{S}_{0, \mathrm{H}} / \mathrm{S}_{0, \mathrm{H} 2}$ & $1 / 0.7$ \\
Gas source temperatures $(\mathrm{K}) \mathrm{T}_{0, \mathrm{H}} / \mathrm{T}_{0, \mathrm{H} 2}$ & 700 \\
Injected $\mathrm{H}_{2}(v)$ vibrational distribution & see Fig. 4 from [1] \\
\hline \hline
\end{tabular}


Table II. List of the most significant volume processes included in the model.

\begin{tabular}{ll}
\hline Reaction & Process
\end{tabular}

Ref.

1) electron atom elastic collision

$\mathrm{e}+\mathrm{H} \rightarrow \mathrm{e}+\mathrm{H}$

[27]

2) electron atom ionization

3) electron vibrational excitation $\mathrm{eV}$

4) electron vibrational excitation $\mathrm{EV}\left(\right.$ via: $\left.\mathrm{B}^{1} \Sigma_{\mathrm{u}}^{+}, \mathrm{C}^{1} \Pi_{\mathrm{u}}\right)$

$\mathrm{e}+\mathrm{H} \rightarrow 2 \mathrm{e}+\mathrm{H}^{+}$

5) electron excitation $\mathrm{eE}$

(via: $\mathrm{B}^{1} \Sigma_{\mathrm{u}}{ }^{+}, \mathrm{C}^{1} \Pi_{\mathrm{u}}, \mathrm{D}^{, 1} \Pi_{\mathrm{u}}^{+}, \mathrm{B}^{, 1} \Sigma_{\mathrm{u}}^{+}, \mathrm{D}^{1} \Pi_{\mathrm{u}}^{+}, \mathrm{BU} \Sigma, \mathrm{a}^{3} \Sigma_{\mathrm{g}}{ }^{+}$)

$$
\begin{gathered}
\mathrm{e}+\mathrm{H}_{2}(v) \leftrightarrow \mathrm{e}+\mathrm{H}_{2}(w) \\
\mathrm{e}+\mathrm{H}_{2}(v) \rightarrow \mathrm{e}+\mathrm{H}_{2}(w)+\mathrm{h} v \\
\mathrm{e}+\mathrm{H}_{2}(v) \rightarrow \mathrm{e}+\mathrm{H}_{2}{ }^{*} \\
\mathrm{e}+\mathrm{H}_{2}(v) \rightarrow 2 \mathrm{e}+\mathrm{H}_{2}{ }^{+} \\
\mathrm{e}+\mathrm{H}_{2}(v) \rightarrow \mathrm{H}+\mathrm{H}
\end{gathered}
$$

7) electron dissociation $\mathrm{eD}$

(via: $\left.\mathrm{B}^{1} \Sigma_{\mathrm{u}}{ }^{+}, \mathrm{C}^{1} \Pi_{\mathrm{u}}, \mathrm{D}^{1}{ }^{1} \Pi_{\mathrm{u}}{ }^{+}, \mathrm{B}^{1}{ }^{1} \Sigma_{\mathrm{u}}^{+}, \mathrm{D}^{1} \Pi_{\mathrm{u}}{ }^{+}, \mathrm{BU} \Sigma, \mathrm{e}^{3} \Sigma_{\mathrm{g}}{ }^{+}, \mathrm{c}^{3} \Pi_{\mathrm{u}}, \mathrm{b}^{3} \Sigma_{\mathrm{u}}\right)$

$$
\begin{gathered}
\mathrm{e}+\mathrm{H}_{2}(v) \rightarrow 2 \mathrm{e}+\mathrm{H}+\mathrm{H}^{+} \\
\mathrm{e}+\mathrm{H}_{2}(v) \rightarrow \mathrm{H}+\mathrm{H}^{-}
\end{gathered}
$$

8) electron dissociative ionization: eDI (via: $\mathrm{X}^{2} \Sigma \mathrm{g}^{+},{ }^{2} \Sigma_{\mathrm{u}}$ )

9) electron dissociative attachment: eDA

10) Coulomb collisions:

$$
\begin{gathered}
\mathrm{e}+\mathrm{e} ; \mathrm{H}^{+}+\mathrm{H}^{+} ; \mathrm{H}_{2}{ }^{+}+\mathrm{H}_{2}{ }^{+} \mathrm{e}+\mathrm{H}^{+} ; \\
\mathrm{e}+\mathrm{H}_{2}{ }^{+} ; \mathrm{H}^{+}+\mathrm{H}_{2}{ }^{+}
\end{gathered}
$$$$
\mathrm{H}^{+}+\mathrm{H} \rightarrow \mathrm{H}+\mathrm{H}^{+}
$$

11) proton charge exchange: $\mathrm{pCX}$

12) proton vibrational excitation: $\mathrm{pV}$

13) proton conversion: $\mathrm{pC}$

14) proton dissociation: $p$ Vdiss

15) electron detachment:

16) mutual neutralization with $\mathrm{H}^{+}$:

17) associative detachment with $\mathrm{H}^{+}$:

$\mathrm{H}^{+}+\mathrm{H}_{2}(v) \rightarrow \mathrm{H}^{+}+\mathrm{H}_{2}(w)$

$$
\mathrm{H}^{+}+\mathrm{H}_{2}(v) \rightarrow \mathrm{H}_{2}^{+}+\mathrm{H}
$$

$\mathrm{H}^{+}+\mathrm{H}_{2}(v) \rightarrow \mathrm{H}^{+}+\mathrm{H}+\mathrm{H}$

18) associative detachment with $\mathrm{H}$ :

$\mathrm{e}+\mathrm{H}^{-} \rightarrow 2 \mathrm{e}+\mathrm{H}$

$$
\mathrm{H}^{-}+\mathrm{H}^{+} \rightarrow 2 \mathrm{H}
$$

$\mathrm{H}^{-}+\mathrm{H}^{+} \rightarrow \mathrm{H}_{2}^{+}+\mathrm{e}$

19) non-associative detachment with $\mathrm{H}$ :

$\mathrm{H}^{-}+\mathrm{H} \rightarrow \mathrm{H}_{2}+\mathrm{e}$

$\mathrm{H}^{-}+\mathrm{H} \rightarrow 2 \mathrm{H}+\mathrm{e}$

20) electron detachment with $\mathrm{H}_{2}$ :

$\mathrm{H}^{-}+\mathrm{H}^{2} \rightarrow \mathrm{H}_{2}+\mathrm{e}$

21) elastic collision with $\mathrm{H}^{+}$:

$\mathrm{H}^{-}+\mathrm{H}^{+} \rightarrow \mathrm{H}^{-}+\mathrm{H}^{+}$

22) charge exchange with $H$ :

$\mathrm{H}^{-}+\mathrm{H} \rightarrow \mathrm{H}+\mathrm{H}^{-}$ 
Table III. Parameters used for the surface negative ion production [36].

\begin{tabular}{ccc}
\hline \hline Parameters & $\begin{array}{c}\text { Ions }\left(\mathbf{H}^{+}, \mathbf{H}_{2}{ }^{+}\right) \\
\text {per nucleus }\end{array}$ & $\begin{array}{c}\text { Neutrals }\left(\mathbf{H}, \mathbf{H}_{2}\right) \\
\text { per nucleus }\end{array}$ \\
\hline Reflection coefficients $R_{\mathrm{N}}, R_{\mathrm{E}}$ & numerical fit $f\left(E_{\text {in }}\right)$ & numerical fit $f\left(E_{\text {in }}\right)$ \\
$R_{\mathrm{N}} \eta_{0}$ [eq. (5)] & 0.30 & 0.42 \\
$E_{\text {th }} / R_{\mathrm{E}}$ [eq. (5)] & $2.0 \mathrm{eV}$ & $1.05 \mathrm{eV}$ \\
$\phi$ [eq. (6)] & $/$ & $1.5 \mathrm{eV}$ \\
$E_{\mathrm{A}}$ [eq. (6)] & $/$ & $0.75 \mathrm{eV}$ \\
\hline \hline
\end{tabular}




\section{Figure captions}

Fig. 1 (Color online). Schematic diagram of the simulation model showing the two different axial lines considered.

Fig. 2 Axial profile of the magnetic filter field used in the simulation [eq. (3)].

Figs. 3 (Color online). Time evolution of (a) charged and (b) neutral macroparticle number into the entire domain of simulation for the case $B_{\text {peak }}=4 \mathrm{mT}$ and $\Phi_{\mathrm{PG}}=0 \mathrm{~V}$.

Fig. 4 Axial profiles of the plasma potential for the two different line considered: extraction hole (dashed line) and PG surface (full line) for the case $B_{\text {peak }}=4 \mathrm{mT}$ and $\Phi_{\mathrm{PG}}=0 \mathrm{~V}$.

Figs. 5 (Color online). Axial profiles of the plasma density for the two different line considered: (a) extraction hole and (b) PG surface for the case $B_{\text {peak }}=4 \mathrm{mT}$ and $\Phi_{\mathrm{PG}}=0 \mathrm{~V}$.

Fig. 6 (Color online). Axial profiles of the different contribution to the negative ion density in line B for the case $B_{\text {peak }}=4 \mathrm{mT}$ and $\Phi_{\mathrm{PG}}=0 \mathrm{~V}$.

Fig. 7 (Color online). Axial profile of elementary reaction rate of the most important processes involving the production and destruction of negative ions for the case $B_{\text {peak }}=4 \mathrm{mT}$ and $\Phi_{\mathrm{PG}}=0 \mathrm{~V}$.

Fig. 8 Axial profile of electron temperature for line B without magnetic filter (dashed line) and using a magnetic filter with $B_{\text {peak }}=4 \mathrm{mT}$ (full line). In both the cases $\Phi_{\mathrm{PG}}=0 \mathrm{~V}$.

Fig. 9 (Color online). Axial profile of electron and $\mathrm{H}^{-}$density for line B without magnetic filter (dashed line) and using a magnetic filter with $B_{\text {peak }}=4 \mathrm{mT}$ (full line). In both the cases $\Phi_{\mathrm{PG}}=0 \mathrm{~V}$.

Fig. 10 (Color online). Axial profiles of plasma potential for line B using four different PG bias $\Phi_{\mathrm{PG}}: 0 \mathrm{~V}, 10 \mathrm{~V}, 20 \mathrm{~V}$ and $36 \mathrm{~V}$. In all the cases $B_{\text {peak }}=4 \mathrm{mT}$.

Fig. 11 (Color online). Axial profiles of electron and $\mathrm{H}^{-}$density for line $\mathrm{B}$ using two different PG bias: $0 \mathrm{~V}$ (dashed line) and $36 \mathrm{~V}$ (full line). In both the cases $B_{\text {peak }}=4$ $\mathrm{mT}$.

Fig. 12 Axial profiles of $\mathrm{H}^{-}$temperature for line $\mathrm{B}$ using two different $\mathrm{PG}$ bias: $0 \mathrm{~V}$ (dashed line) and $36 \mathrm{~V}$ (full line). In both the cases $B_{\text {peak }}=4 \mathrm{mT}$. 


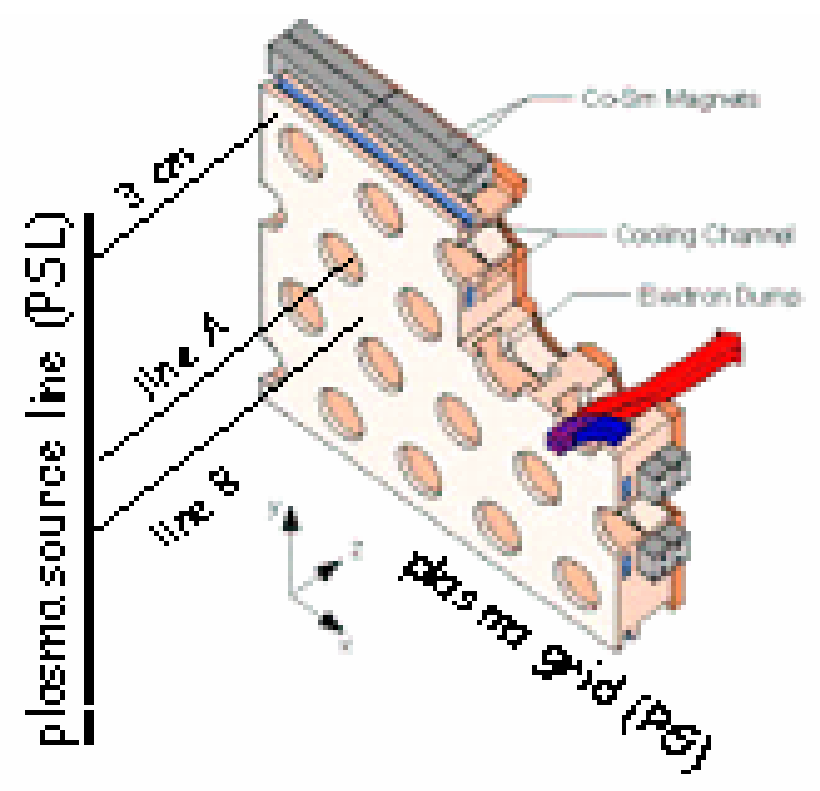

Fig.1 


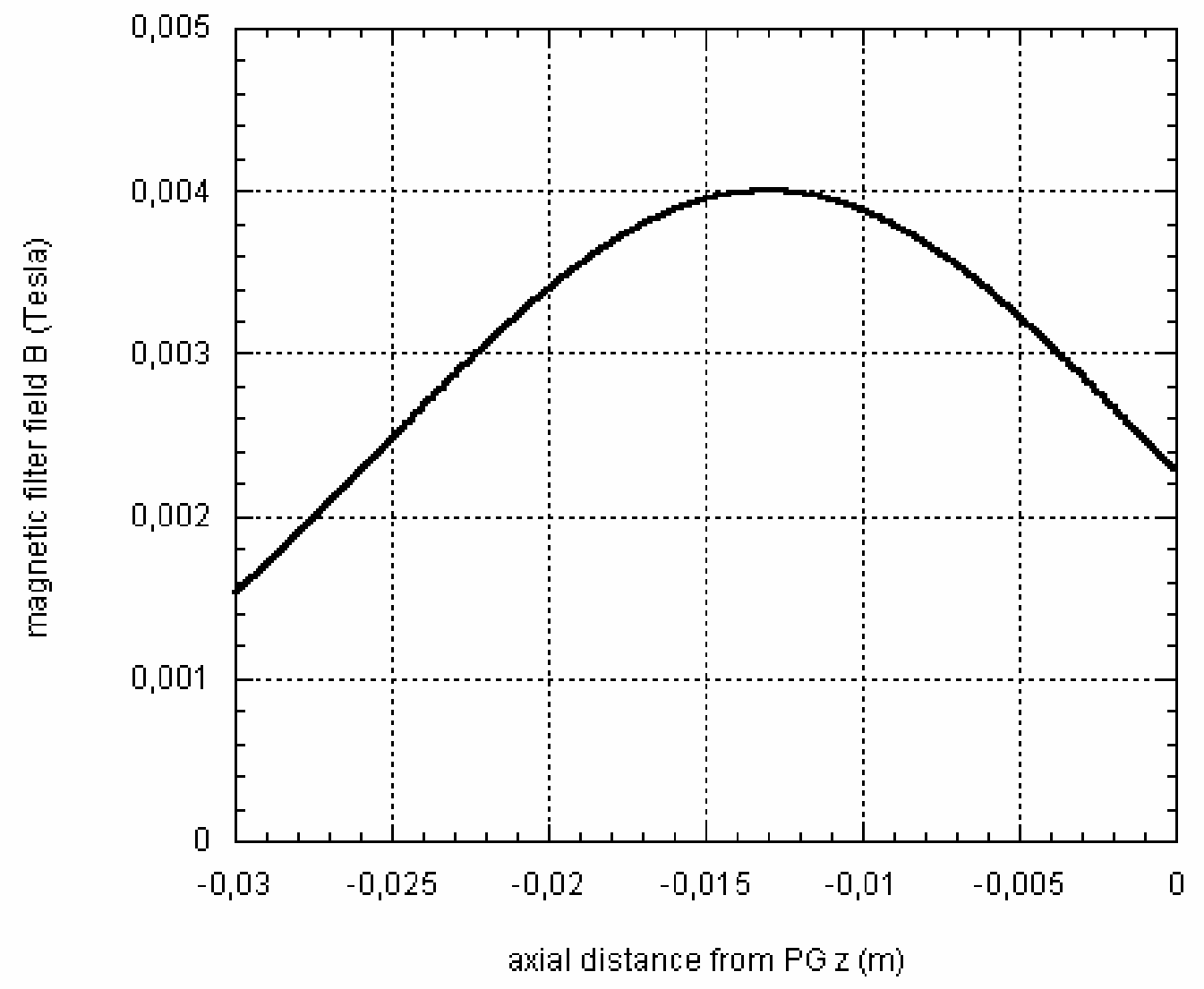

Fig. 2 

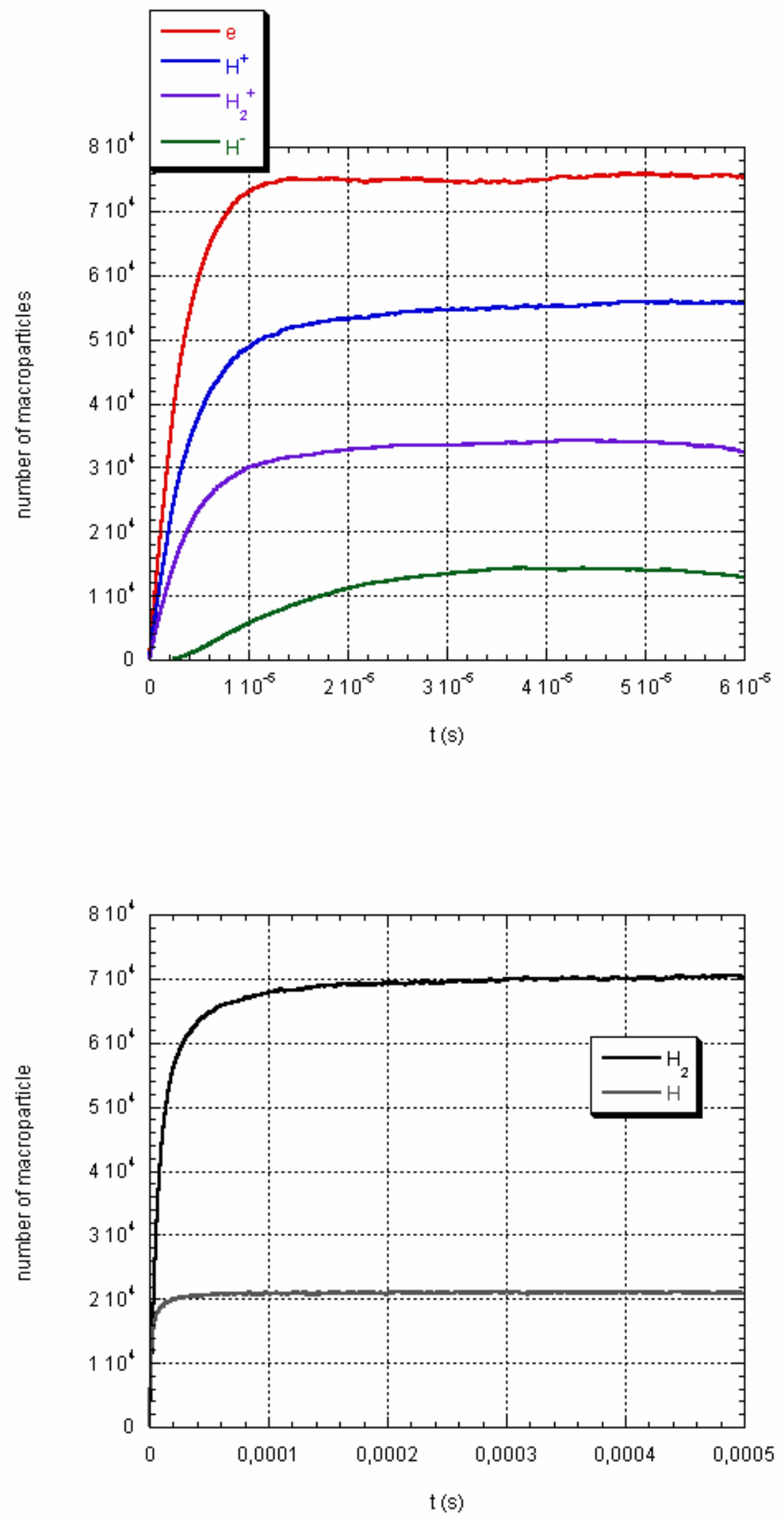

Fig. 3 


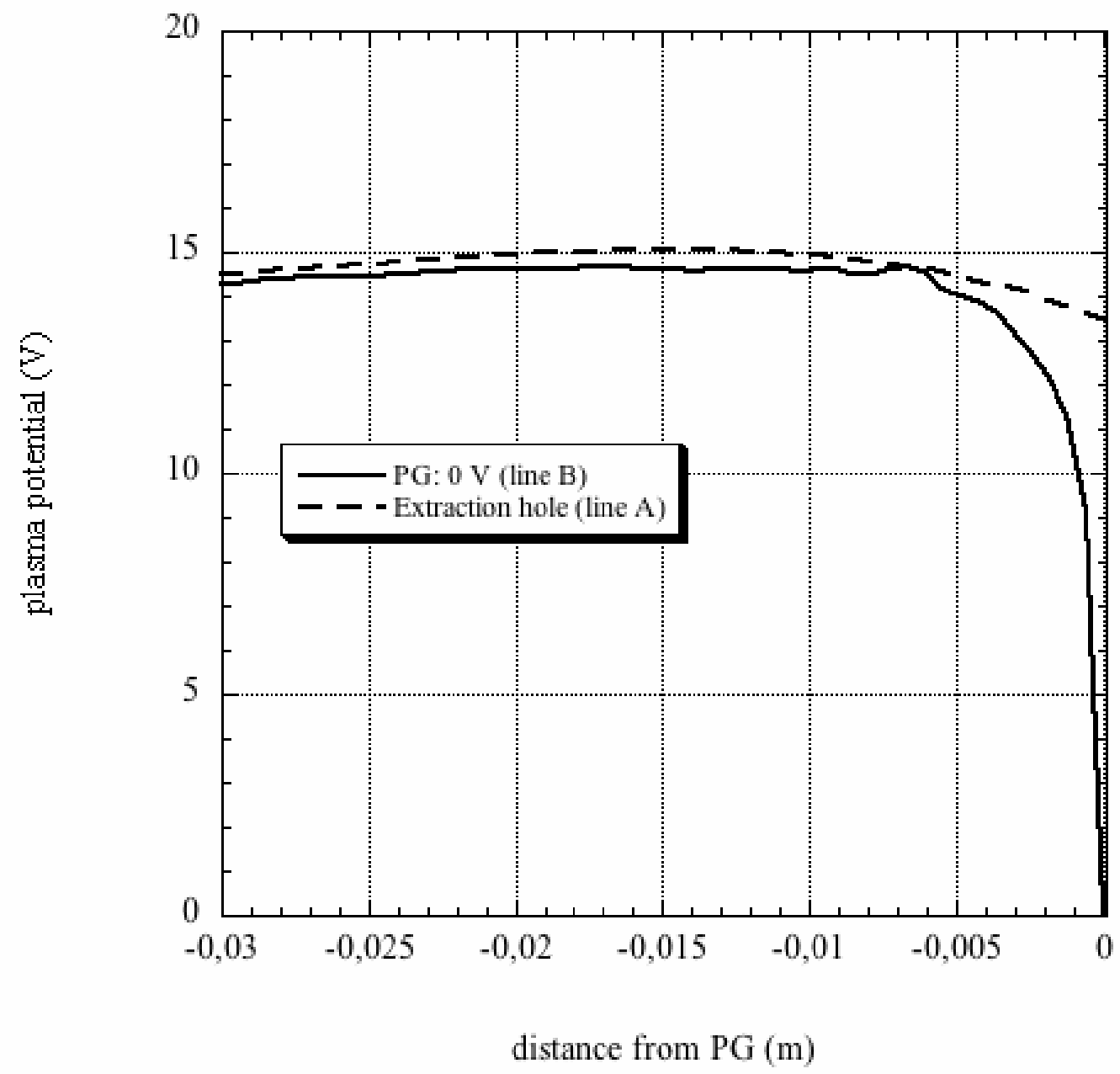

Fig. 4 

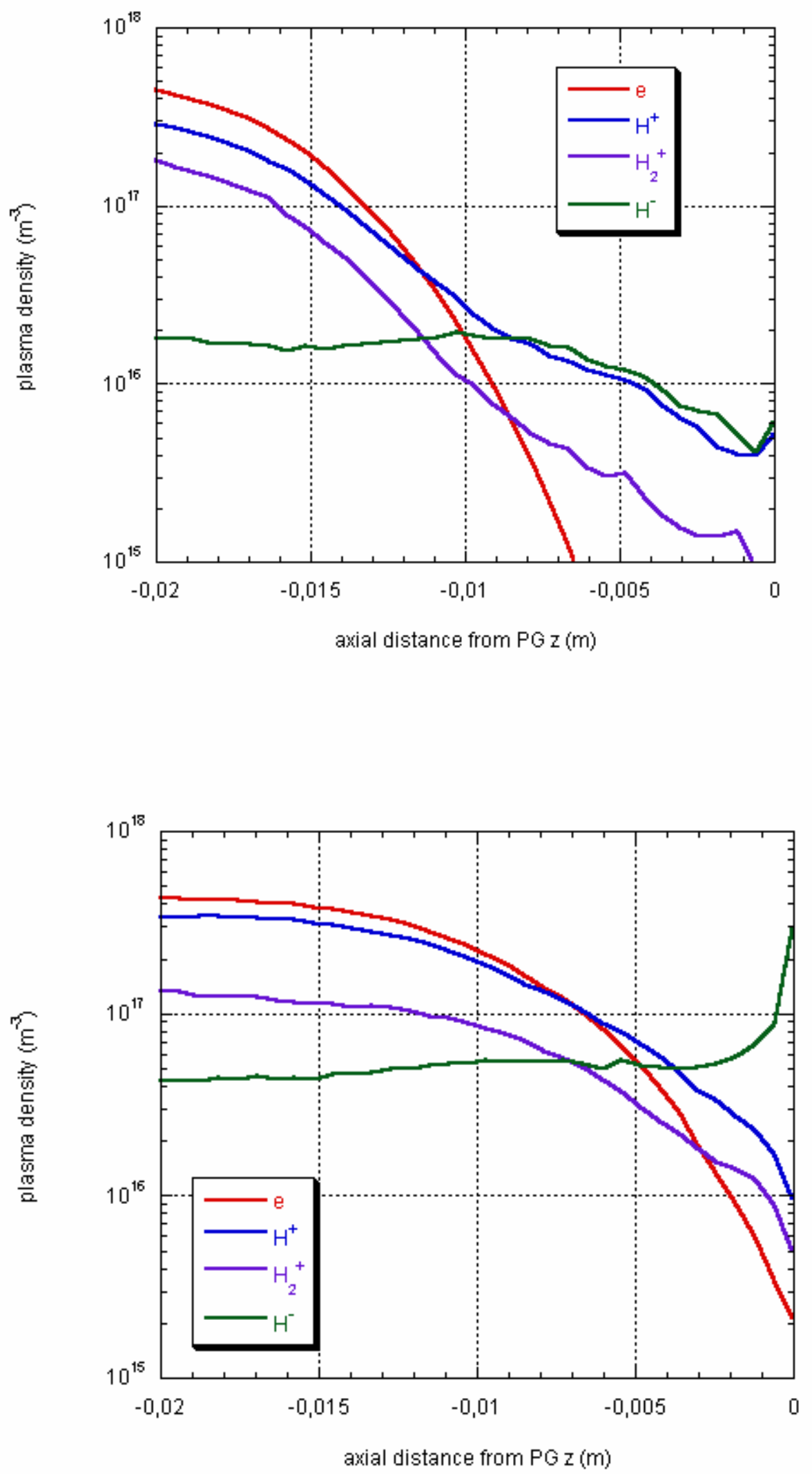

Fig. 5 


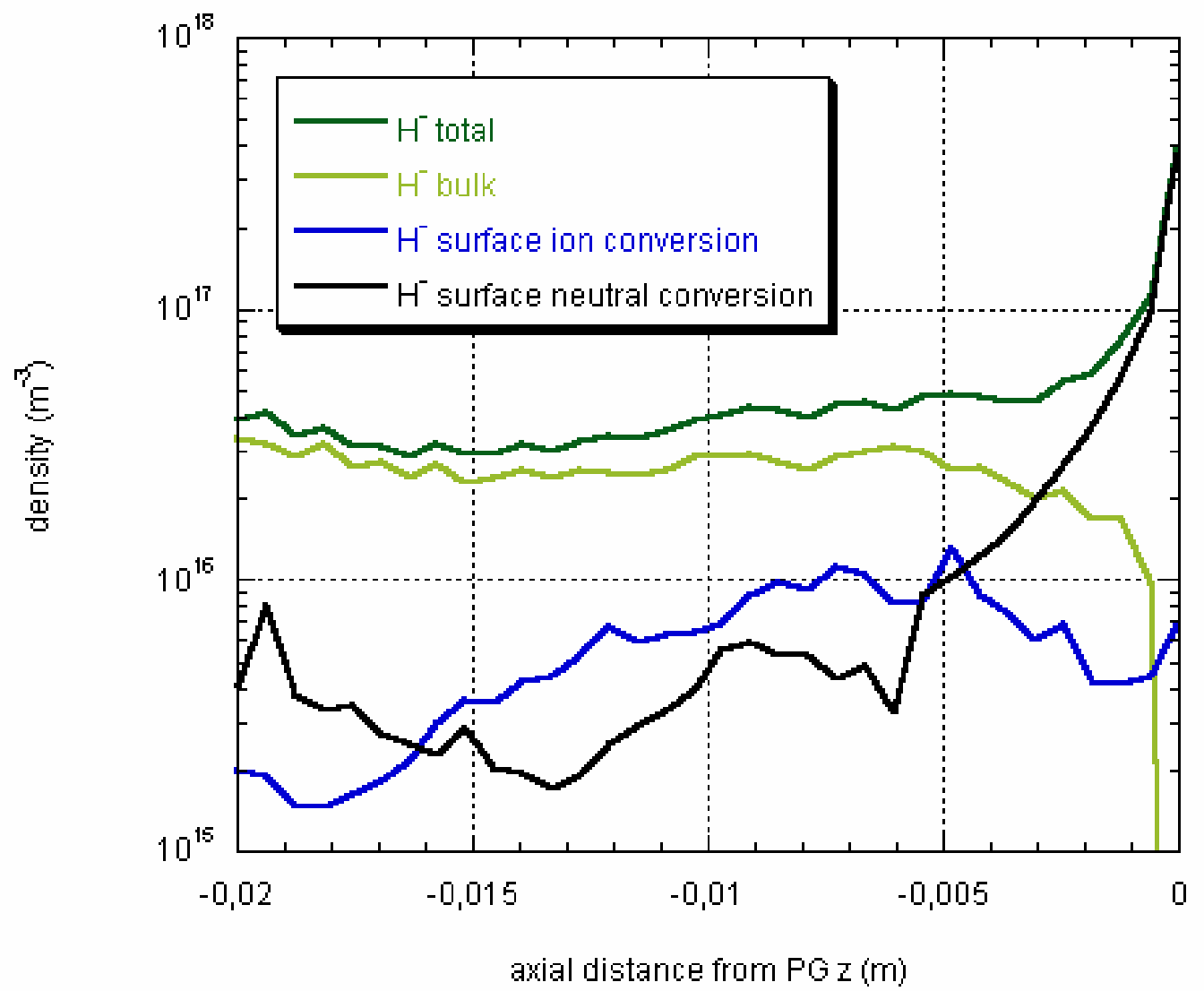

Fig. 6 


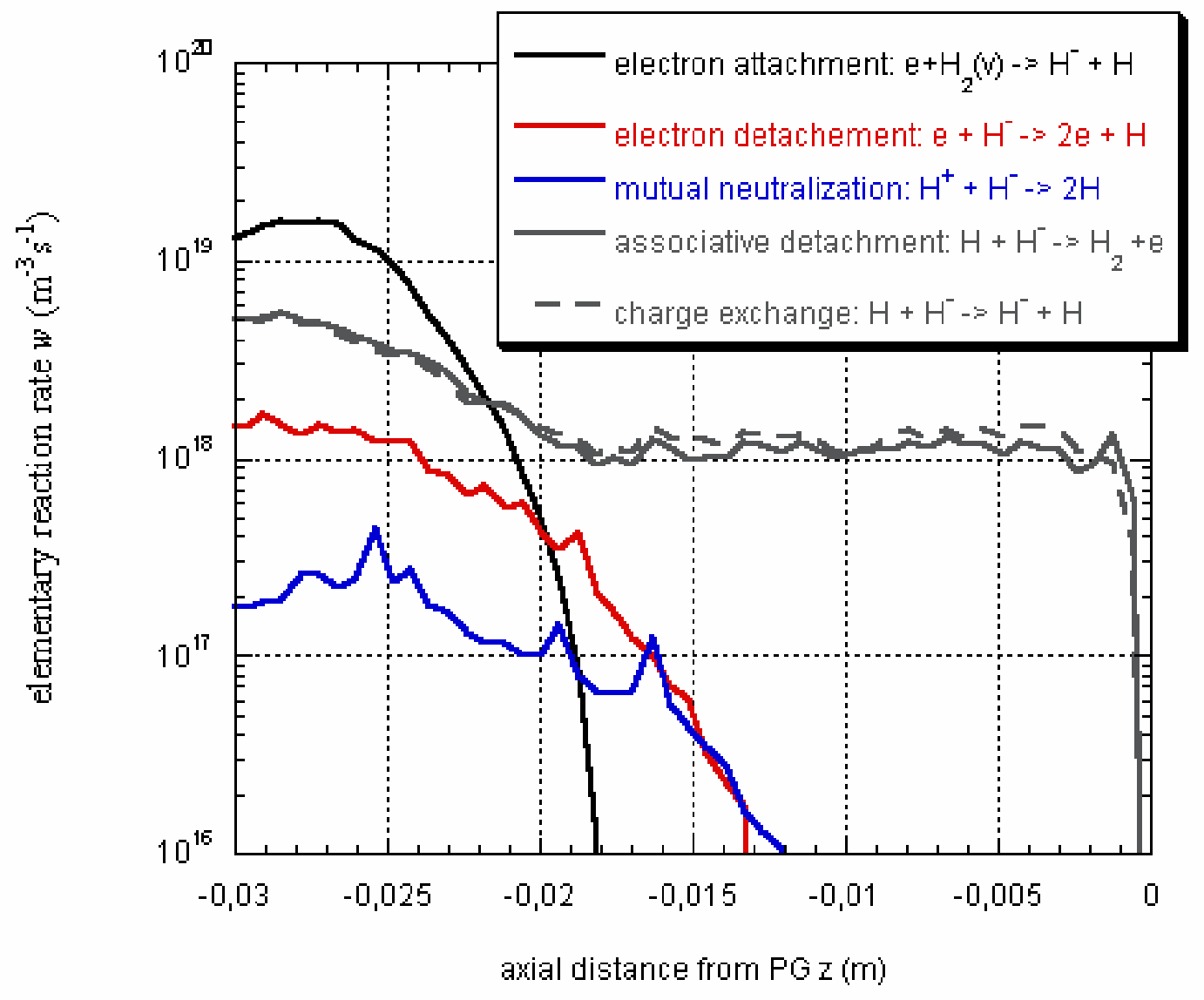

Fig. 7 


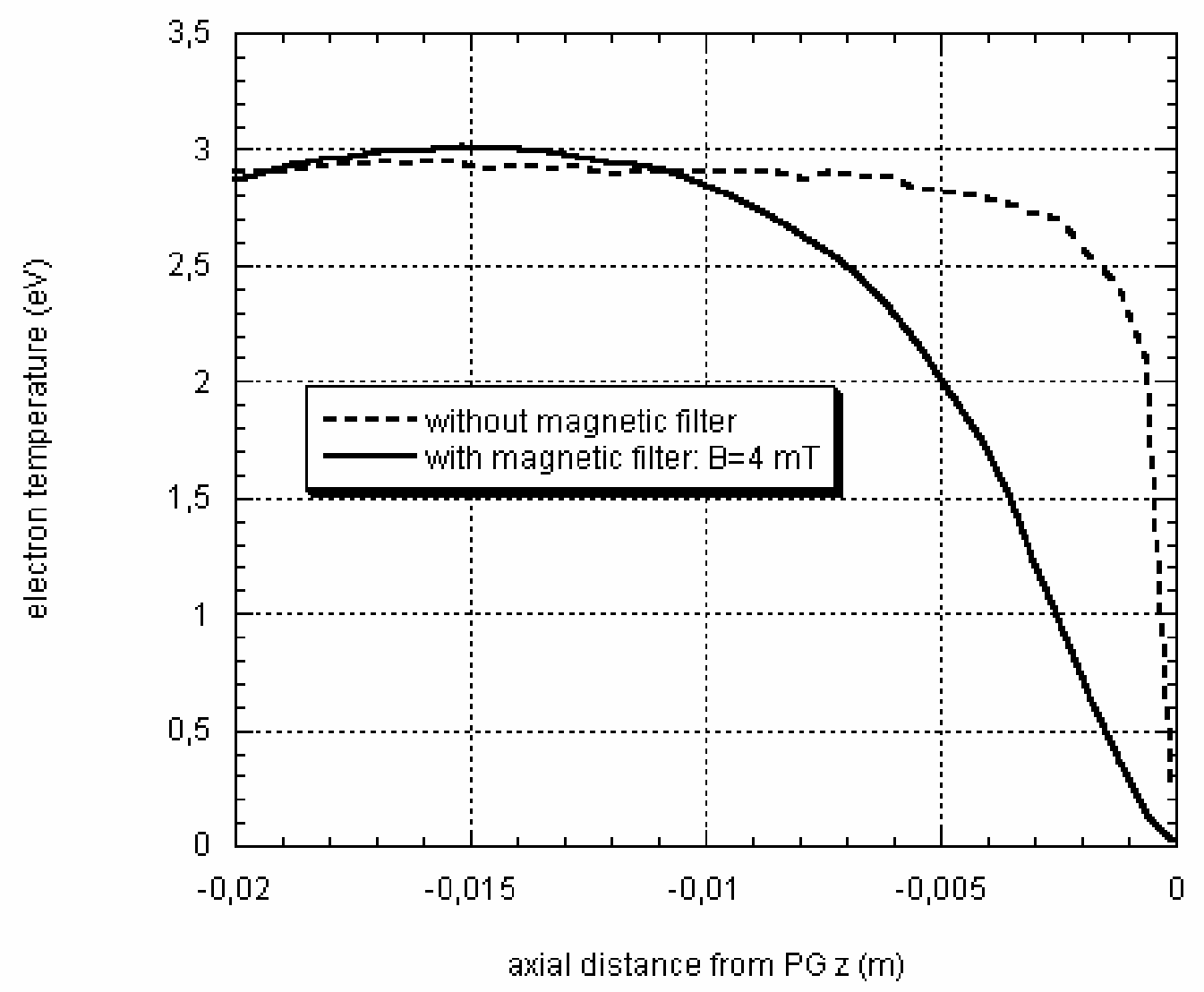

Fig. 8 


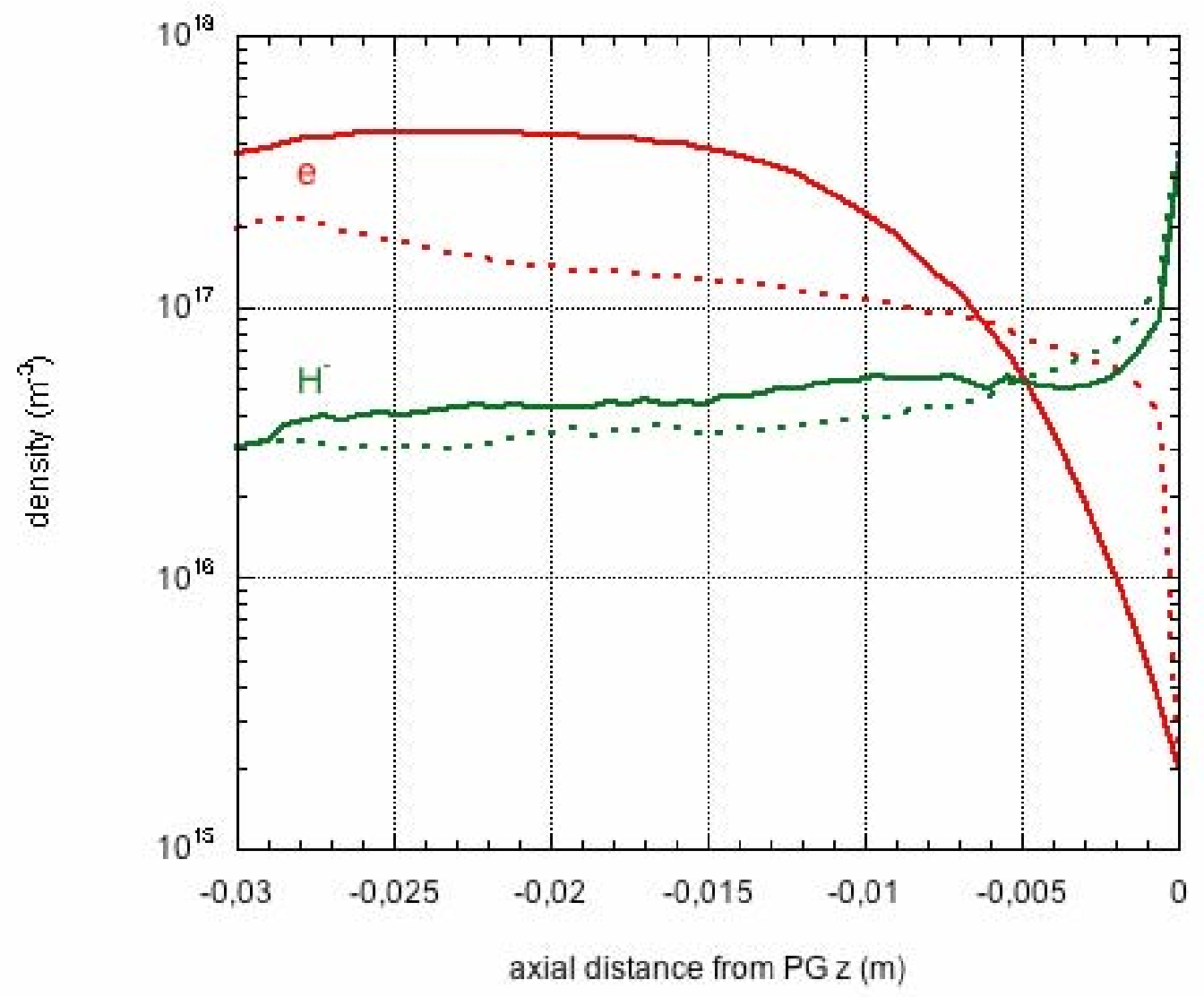

Fig. 9 


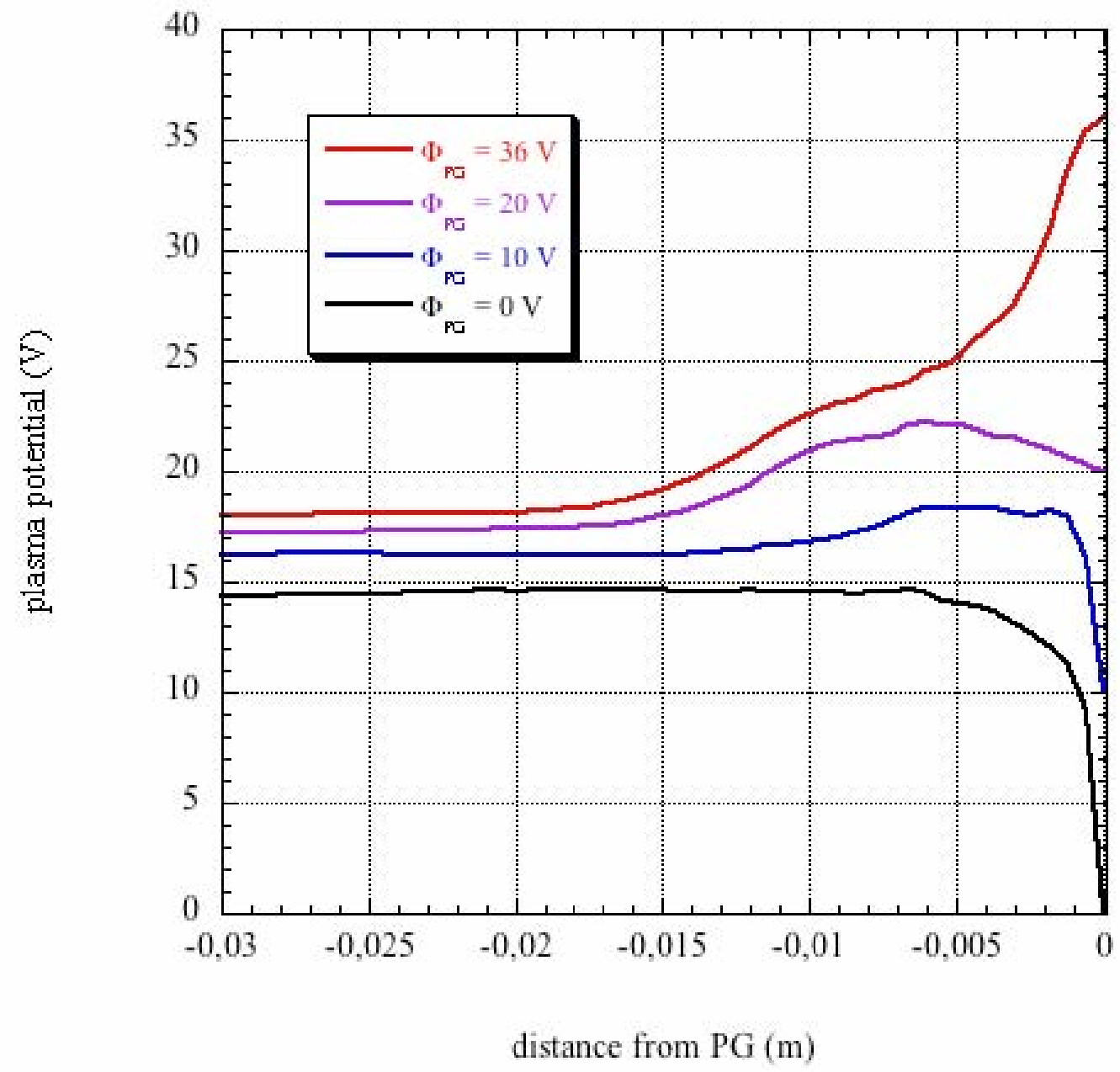

Fig. 10 


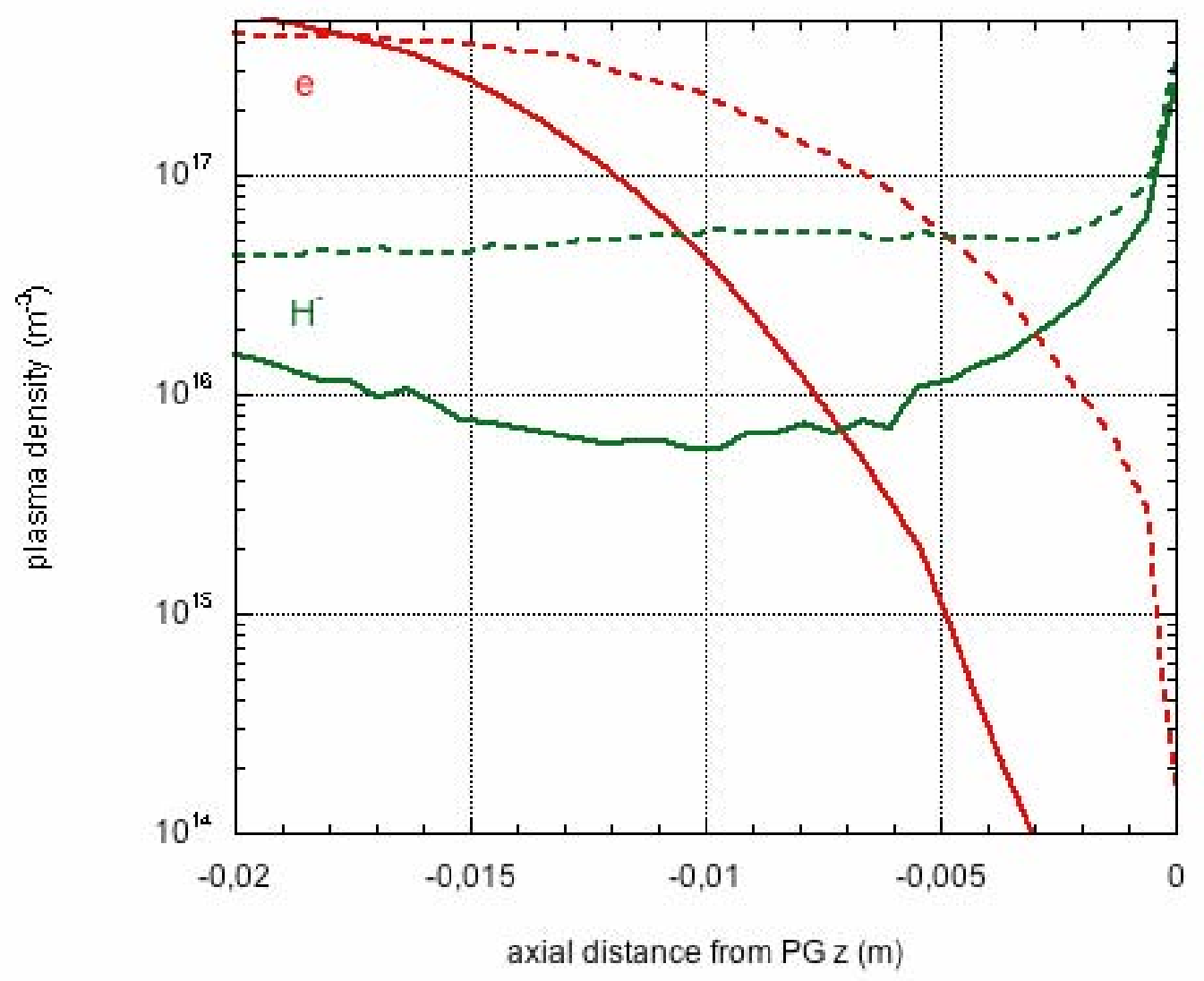

Fig. 11 


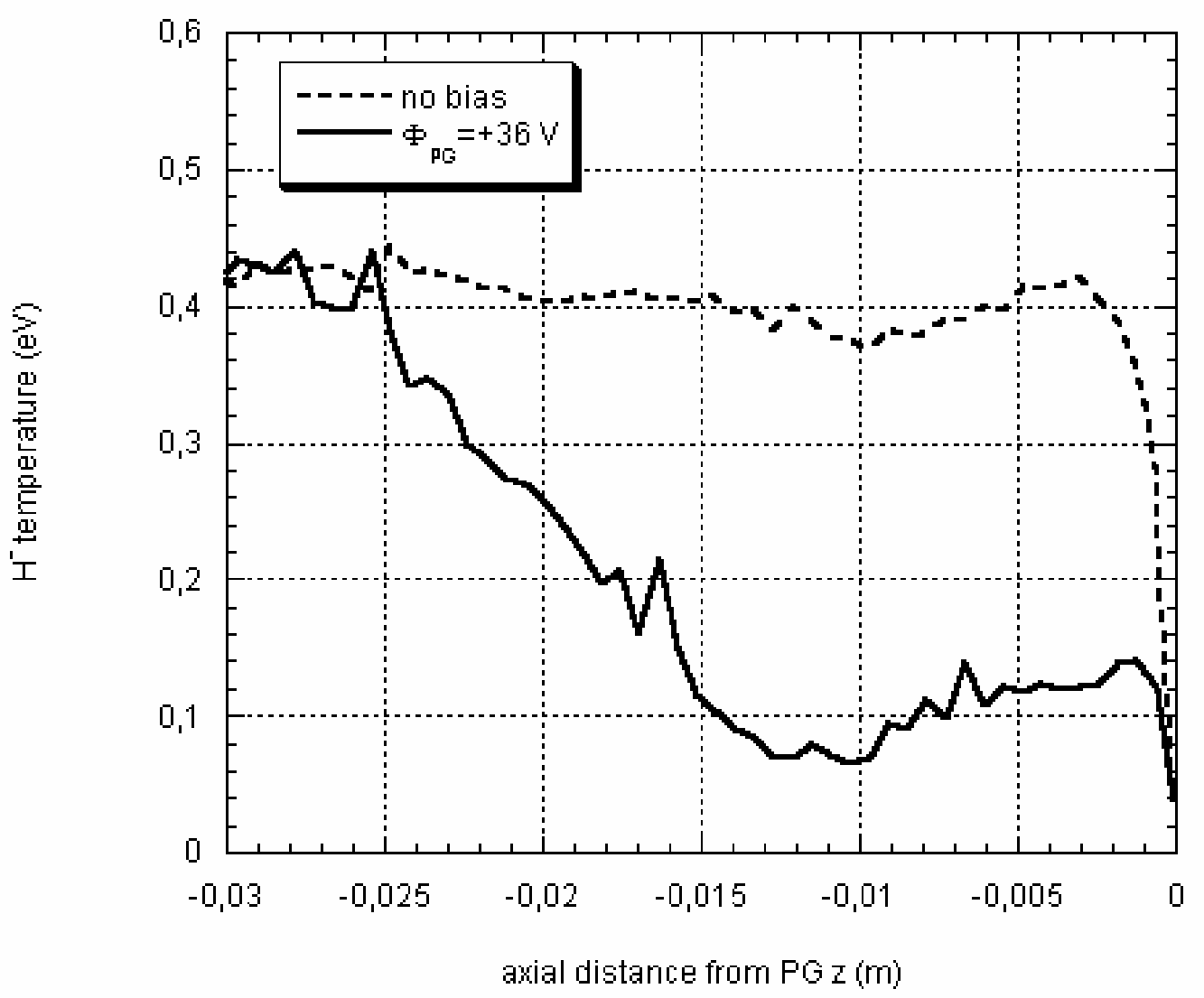

Fig. 12 